\title{
To the Occiput or Not? C1-C2 Ligamentous Laxity in Children with Down Syndrome
}

\author{
Kris Siemionow ${ }^{1,2}$ Dean Chou $^{3}$ \\ ${ }^{1}$ Department of Orthopaedics and Neurosurgery, University of Illinois, \\ Chicago, Illinois, United States \\ 2 Illinois Spine and Scoliosis Center, Chicago, Illinois, United States \\ ${ }^{3}$ The UCSF Spine Center, University of California San Francisco, \\ San Francisco, California, United States
}

Evid Based Spine Care J 2014;5:112-118.
Address for correspondence Kris Siemionow, MD, Illinois Spine and Scoliosis Center, 12701 W. 143rd Street, Suite 110, Homer Glen, IL 60491, United States (e-mail: siemiok@gmail.com).

\begin{abstract}
Keywords

- C1-C2 instability

- basilar invagination

- Down syndrome

- pediatric

- occiput

- os odontoideum

Study Design Retrospective case review.

Objective Atlantoaxial instability with and without basilar invagination poses a considerable challenge in management regarding reduction, surgical approach, decompression, instrumentation choice, and extent of fusion. A variety of strategies have been described to reduce and stabilize cranial settling with basilar invagination. Modern instrumentation options included extension to the occiput, $\mathrm{C} 1-\mathrm{C} 2$ transarticular fixation, and C1 lateral mass-C2 pars among others. Since not all cases of cranial settling are the same, their treatment strategies also differ. Factors such as local vascular anatomy, amount of subluxation, need for distraction, and shape of occipital condyles will dictate level and type of instrumentation. The objective of this study was to outline treatment options and provide a rationale for the surgical plan.

Methods Two cases of $\mathrm{C} 1-\mathrm{C} 2$ instability in patients with Down syndrome are described. Case 2 underwent $\mathrm{C} 1-\mathrm{C} 2$ instrumented fusion, whereas case 1 involved posterior instrumented fusion to the occiput.

Results Both patients tolerated the procedures well. There were no complications. Minimum follow-up was 1 year. There was no loss of reduction. Solid arthrodesis was achieved in both cases.

Conclusion Successful reduction can be achieved with both $\mathrm{C} 1-\mathrm{C} 2$ instrumented fusion as well as $\mathrm{O}-\mathrm{C}$ instrument fusion. Factors such as local vascular anatomy, amount of subluxation, need for distraction, and shape of occipital condyles will dictate level and type of instrumentation.
\end{abstract}

\section{Introduction}

Atlantoaxial instability with and without basilar invagination poses a considerable challenge in management regarding reduction, surgical approach, decompression, instrumentation choice, and extent of fusion. A variety of strategies have been described to reduce and stabilize cranial settling with basilar invagination. ${ }^{1-6}$ Modern instrumentation options included extension to the occiput, $\mathrm{C} 1-\mathrm{C} 2$ transarticular fixation, and C1 lateral mass-C2 pars among others. Since not all cases of cranial settling are the same, their treatment strategies also differ.

Severe C1-C2 instability can sometimes result in actual basilar invagination or cranial settling. As the $\mathrm{C} 1-\mathrm{C} 2$ complex becomes unstable, the ring of $\mathrm{C} 1$ can push the spinal cord and brainstem into the odontoid process. In addition, if the $\mathrm{C} 1-\mathrm{CO}$ received

May 31, 2013

accepted

June 3, 2014 (c) 2014 Georg Thieme Verlag KG Stuttgart · New York
DOI http://dx.doi.org/ 10.1055/s-0034-1386749. ISSN 1663-7976. 
joint is intact, the cranium will also translate ventrally toward the odontoid. This will result in compression against the brainstem, even though the $\mathrm{C} 1-\mathrm{C} 0$ joint is competent.

In this report, we describe two cases of basilar invagination treated with two different instrumentation options. We provide the rationale for instrumenting to the occiput versus stopping at $\mathrm{C} 1$.

\section{Case Report}

\section{Case 1}

A 14-year-old male patient with Down syndrome who presented with a 4-week history of left upper extremity weakness and torticollis. Preoperative computed tomography (CT) and magnetic resonance imaging (MRI) demonstrated a significant rotatory subluxation with associated spinal cord compression (-Figs. 1 and 2). The patient underwent a trail of preoperative traction which did not result in deformity reduction. He was taken to the operating room where he underwent open instrumented reduction and fusion from occiput to $\mathrm{C} 2$.

After positioning in a Mayfield headholder in a prone position, the occiput, posterior arch of $\mathrm{C} 1$, and posterior elements of C2 were exposed. C2 pars and C1 lateral mass screws placed, followed by placement of an occipital plate. The proximal end of a cobalt-chrome rod was then contoured to approximately 110 to 120 degrees. The rod was secured to the tulips starting distally, and locking caps were applied to the distal instrumentation as well as the occipital plate. The locking caps were then final tightened in the distal portion of the construct and left loose in the occipital plate and $\mathrm{C} 2$. The

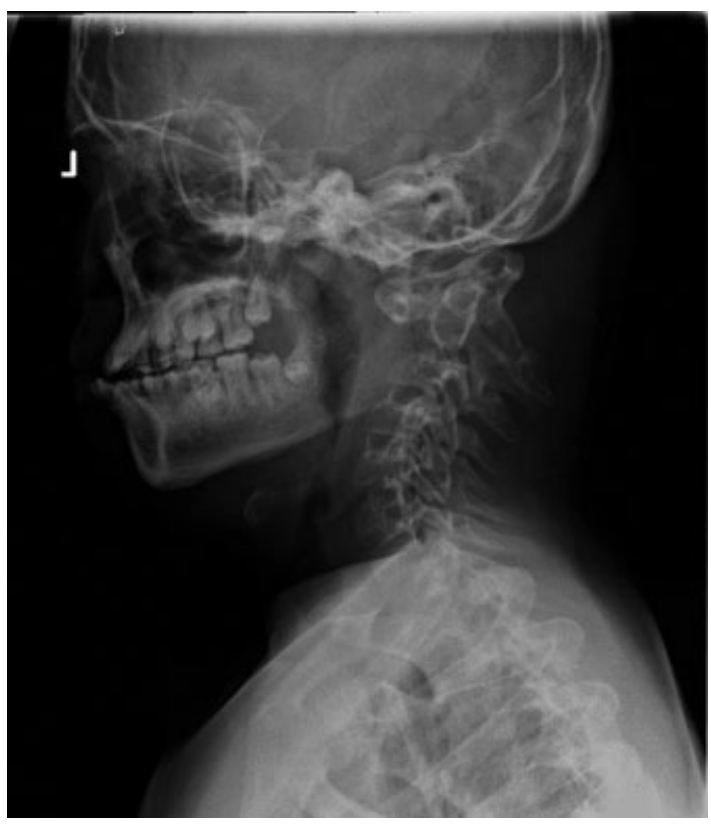

Fig. 1 Preoperative lateral X-ray of cervical spine demonstrating posterior displacement of the dens secondary to C1-C2 instability. The atlantodens interval measured $15.8 \mathrm{~mm}$. A component of rotatory subluxation is also present.

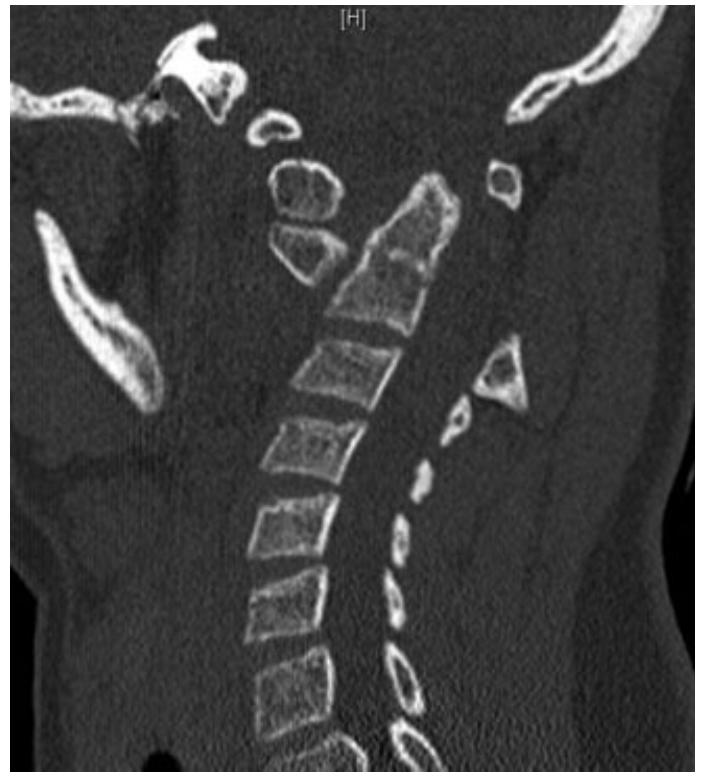

Fig. 2 Computed tomography scan demonstration midline sagittal cut of the cervical spine. Basilar invagination is present in addition to significant rotatory component. The distance between the posterior arch of $\mathrm{C} 1$ and the dens is severely diminished resulting in significant spinal canal stenosis.

rods were made from cobalt-chromium alloy and had a 3.5-mm diameter.

\section{The Reduction Maneuver}

The reduction maneuver involved distraction between the rod holder clamped just proximal to $\mathrm{C} 2$ screw head and the occipital plate (-Fig. 3). Distraction was performed in a controlled fashion in $2 \mathrm{~mm}$ increments. Radiographs were then obtained and occipitocervical alignment was then examined. This maneuver allowed the occiput to migrate superior posterior over the precontoured rod with simultaneous anterior inferior migration of the dens.

Postoperative MRI and CT demonstrate spinal cord decompression and deformity reduction (-Figs. 4 and 5).

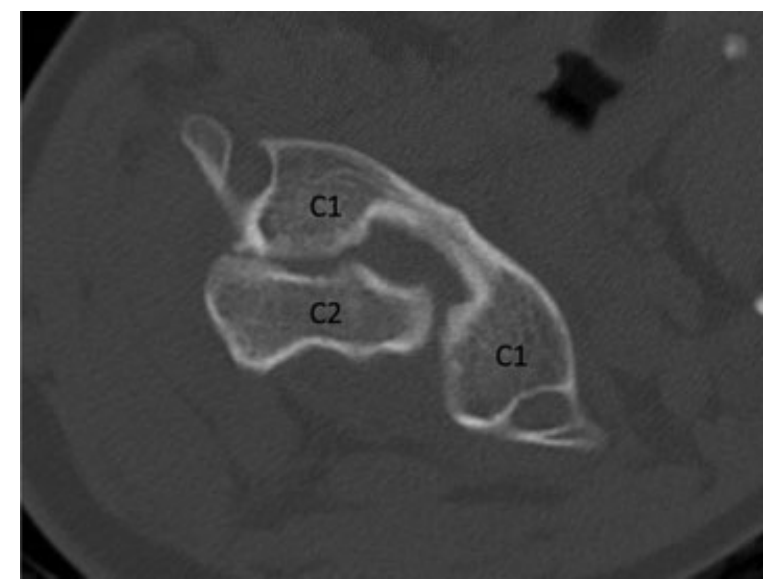

Fig. 3 Axial computed tomography scan demonstrating significant rotatory subluxation with critical spinal stenosis at C1-C2. 


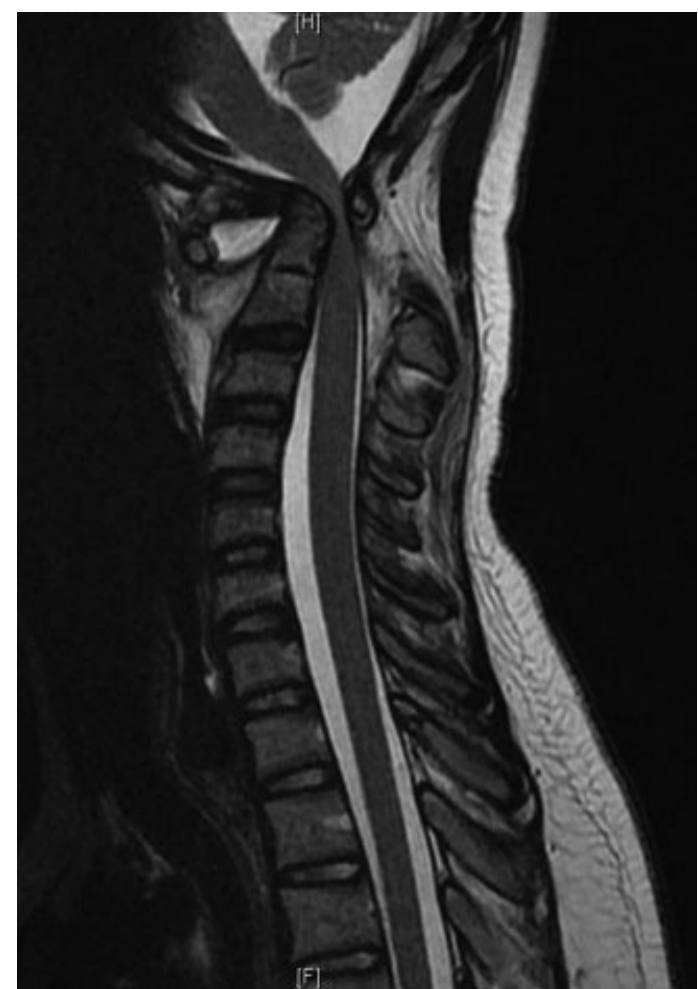

Fig. 4 Sagittal T2-weighted magnetic resonance imaging demonstrating severe spinal cord compression between the posteriorly displaced dens and posterior arch of $\mathrm{C} 1$.

At 1-year follow-up, reduction was maintained and neurologic status recovered to normal.

\section{Case 2}

The patient is a 15-year-old female with Down syndrome who presented with multiple "drop attacks," where she would lose complete tone in her extremities and fall to the ground. The patient had an extensive syncope and seizure work-up, but she was found to have severe cord compression secondary to C1-C2 instability and os odontoideum by MRI and CT (-Figs. 6 and 7). The patient was immediately placed in halo immobilization with attempts to externally reduce the listhesis; however, the subluxation persisted ( $\mathbf{F i g . 8 A}$, B). The patient underwent CT imaging and $\mathrm{X}$-rays, to evaluate her $\mathrm{C} 0-\mathrm{C} 1$ joints and the $\mathrm{C} 1-\mathrm{C} 2$ joints (-Figs. 9A, B, and 10A). It was found that the $\mathrm{CO}-\mathrm{C} 1$ joints were intact, without significant diastasis. Because the $\mathrm{C} 0-\mathrm{C} 1$ joints were found intact by CT scan, it was felt that an attempt to only instrument $\mathrm{C} 1$ and $\mathrm{C} 2$ would be reasonable, even though there would be an intraoperative potential of extending the fusion to the occiput.

The patient was taken to the operating room and subsequently positioned in the halo, with the vest component subsequently removed. After standard exposure, lateral mass screws were placed into $\mathrm{C} 1$, and $\mathrm{C} 2$ pars screws were placed bilaterally. A C1 laminectomy was performed to decompress the spinal cord. The $\mathrm{C} 1-\mathrm{C} 2$ listhesis was subsequently reduced by gentle manual downward pressure on $\mathrm{C} 2$, using a penetrating towel clamp on the $\mathrm{C} 2$ spinous process. After reduction, the $\mathrm{C} 1-\mathrm{C} 2$ was locked into position, lateral fluoroscopy confirmed good reduction, decortication of the C1-C2 joint was performed, and local autograft was placed into the facets. At 5-year follow-up, no revision surgery has been performed (- Fig. 10B).

\section{Discussion}

Management of basilar invagination poses multiple treatment challenges. In the two case examples, we chose two different proximal levels to end our instrumentation. Case 1 involved extending instrumentation up to the occiput. Case 2 had $\mathrm{C} 1$ as the most proximal level. Even though both patients were adolescents with Down syndrome, and on initial evaluation appeared to have the same problem, there are differences between the two cases, which resulted in choosing two different operations. In case 1 , there was a significant rotatory subluxation, which was not present in case 2 . This resulted in both axial and coronal plane deformities, which were not present in the second case. A second reason that the occiput was chosen as the proximal level in case 1 was the amount of intraoperative reduction of $\mathrm{C} 1-\mathrm{C} 2$ achievable, was not similar to that of case 2. Much of this may have been secondary to the longer standing deformity and the coronal and axial rotation that was present in case 1 .

There are several settings in which extending the construct up to the occiput should be considered. Basilar invagination may be associated with condylar dysplasia. Browd et al performed a morphometric analysis in children with Down syndrome, which demonstrated an absence of the normal, concave $\mathrm{C} 1$ superior articular surface anatomy, increasing the chance of occipital cervical (O-C) instability. ${ }^{7}$ A review of 210 patients with Down syndrome revealed that $8.5 \%$ of individuals had a powers ratio of $<0.55$, which was indicative of posterior occipitoatlantal hypermobility. ${ }^{8}$ This patient population has also been shown to fail to develop the curved architecture in the occipital condyle that occurs in agematched controls over time. ${ }^{9}$ Because of these factors, the pathology is not always just at $\mathrm{C} 1-\mathrm{C} 2$ joint, but it is the C0-C1-C2 complex.

The second reason to consider instrumenting the occiput is in the setting of nonreducible cranial settling. Distracting between the occiput and C2 screws allows for controlled reduction of the deformity. ${ }^{10,11}$ The reduction maneuver described above allows the occiput to migrate superior posterior over the precontoured rod with simultaneous anterior-inferior migration of the dens, resulting in restoration of occipitocervical alignment. The prebent rods act as rails and help guide the reduction. Intraoperative fluoroscopy can be used to monitor the degree of reduction. We recommend checking motor-evoked potential every minute during the reduction phase and every 5 minutes thereafter. Clinically, the dura will appear stretched if too much reduction is performed. Any change in motor or sensory potential should be followed by releasing the locking caps, gently reversing the reduction maneuver, and reassessing the neurologic status. A wake-up test can be useful in this setting.

A third reason that fusion to the occiput was chosen in case 1 was that of the axial and coronal plane deformities. The 

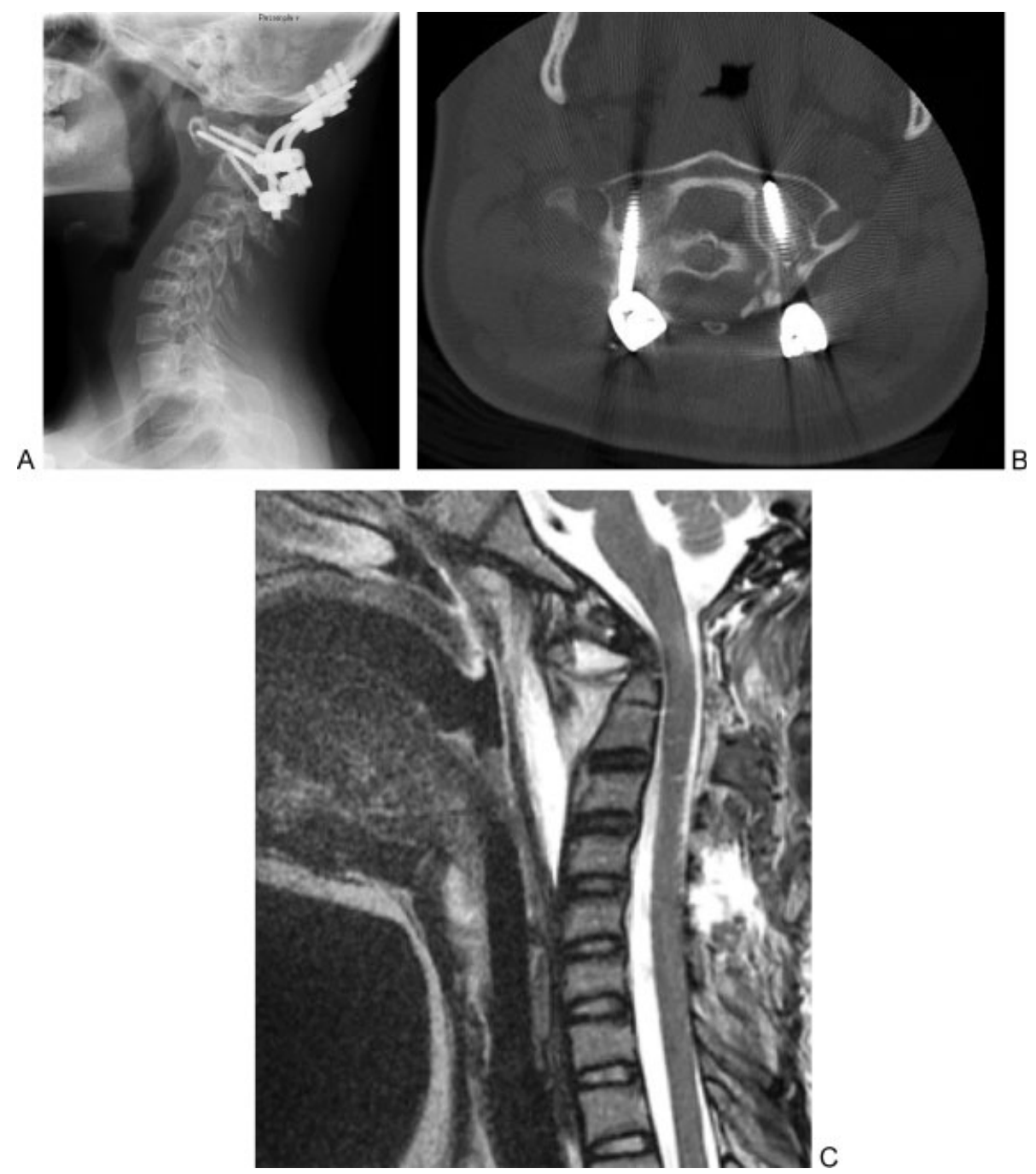

Fig. 5 (A) Postoperative lateral X-ray of cervical spine demonstrating reduction of $\mathrm{C} 1-\mathrm{C} 2$ instability with posterior $\mathrm{O}-\mathrm{C} 1-\mathrm{C} 2$ instrumentation (Harms technique) and fusion. (B) Axial computed tomography at C1-C2 demonstrating reduction of rotatory subluxation. (C) Postoperative sagittal T2-weighted magnetic resonance imaging demonstrating decompression of the spinal cord and reduction of basilar invagination.

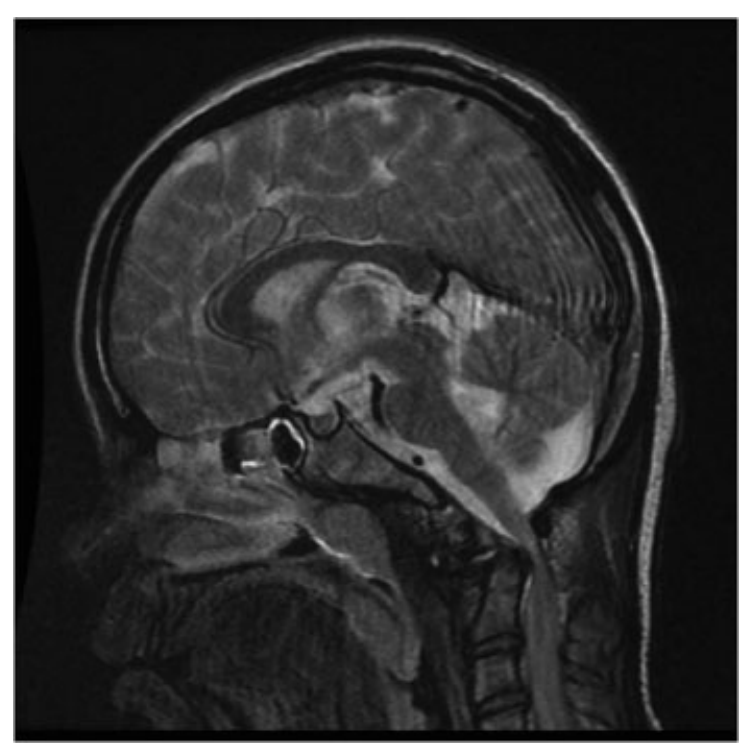

Fig. 6 Sagittal T-2 weight magnetic resonance imaging of the craniocervical junction demonstrating severe spinal cord compression secondary to C1-C2 instability.

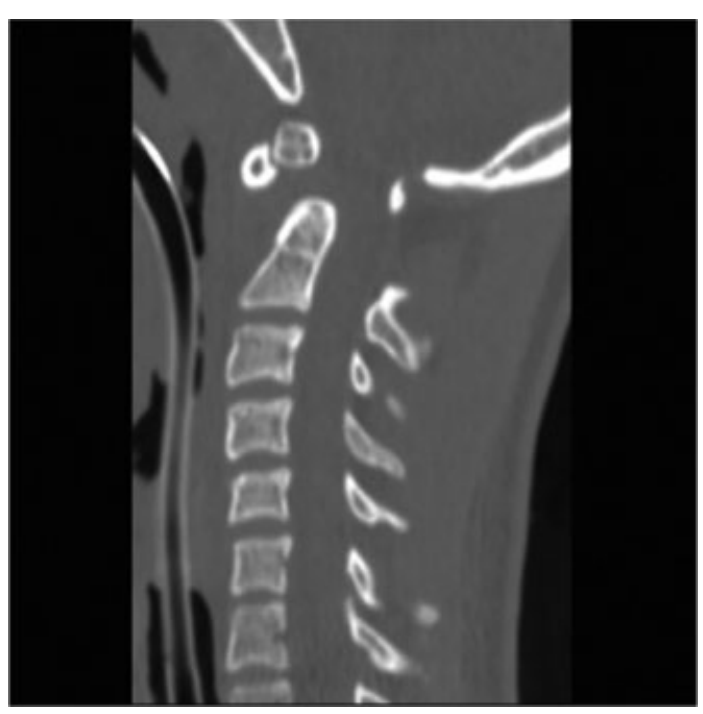

Fig. 7 Computed tomography scan demonstration midline sagittal cut of the cervical spine. An os odontoideum is visible in addition to posterior displacement of the dens. 

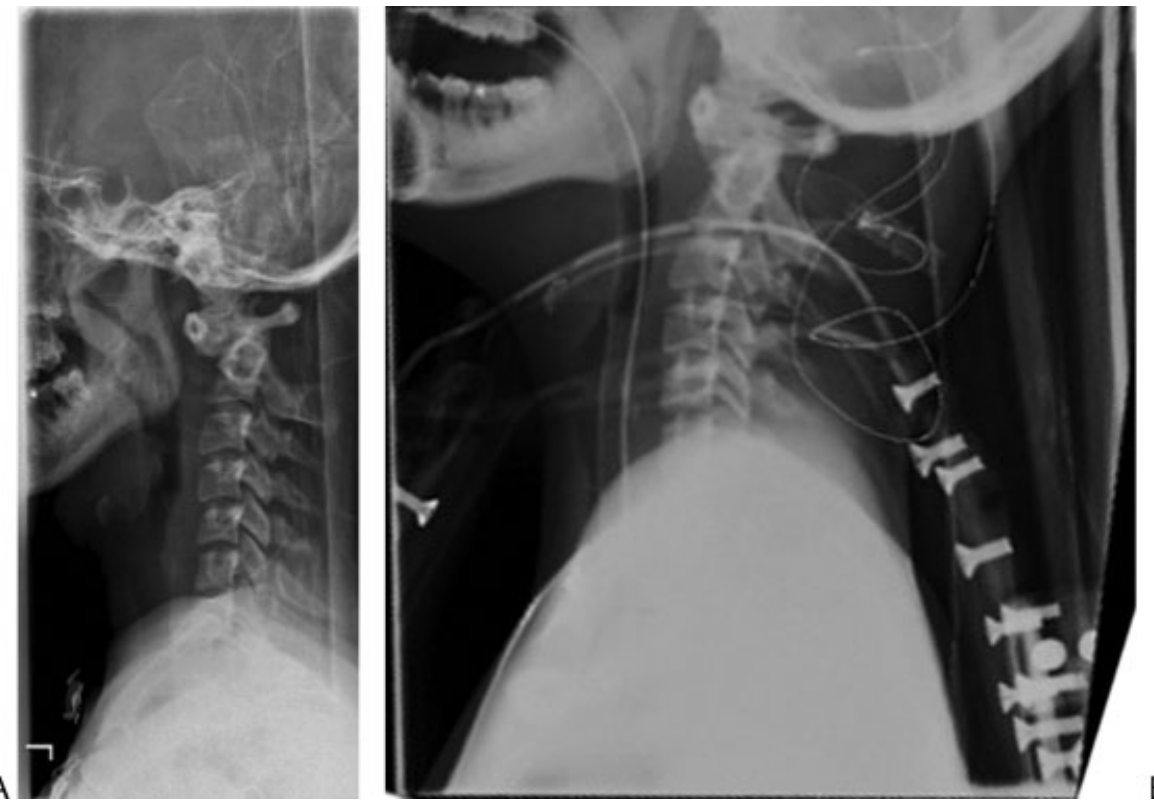

Fig. 8 (A) Lateral X-ray of cervical spine demonstrating posterior displacement of the dens secondary to C1-C2 instability. (B) Lateral X-ray of cervical spine in halo traction demonstrating incomplete reduction of posterior displacement.
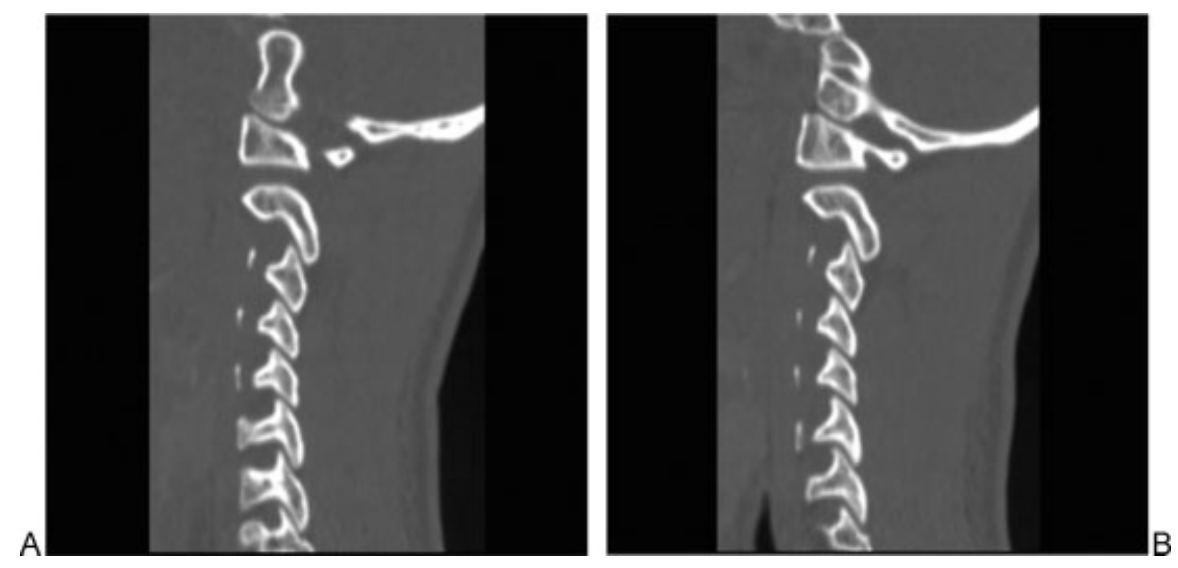

Fig. 9. Sagittal computed tomography scan of the (A) left and (B) right occipitocervical joints demonstrating no evidence of diastasis.

amount of reduction and correction achievable only with C1 fixation was unknown preoperatively, and since a main reason for surgery was to correct the deformity, extension to the occiput was chosen. In case 2 , the occiput- $\mathrm{C} 1$ joints were intact on parasagittal CT imaging; the patient did not have axial or coronal deformity; and near-complete reduction was achievable with just $\mathrm{C} 1-\mathrm{C} 2$ instrumentation intraoperatively.

If the brainstem compression is secondary to $\mathrm{C} 1-\mathrm{C} 2$ instability and not projection of the odontoid process into the posterior fossa (as seen with the odontoid process cephalad to the bottom of the clivus), and the $\mathrm{C} 0-\mathrm{C} 1$ joints are competent, consideration may be given to stopping proximal fusion level at C1. If, however, there is clearly indentation of the odontoid process into the posterior fossa, extension to the occiput would be very important. Another consideration in the decision making would be the underlying pathophysiology of the patient. Because the ligamentous laxity in Down syndrome patients is mainly at $\mathrm{C} 1-\mathrm{C} 2$, consideration for stopping at $\mathrm{C} 1$ could be made; however, in patients with rheumatoid arthritis, there should be a thorough work-up as to whether the pathology is from the $\mathrm{C} 1-\mathrm{C} 2$ joint or from $\mathrm{C} 0-\mathrm{C} 1-\mathrm{C} 2$ complex.

Anatomic considerations may preclude placement of $\mathrm{C} 1$ instrumentation, thus necessitating extension to the occiput. These may include vertebral artery anomalies or lateral mass hypoplasia. ${ }^{12-14}$

Extending the construct to the occiput has been associated with higher rates of pseudarthrosis and complications. ${ }^{15} \mathrm{We}$ feel that instrumenting to $\mathrm{C} 1$ is sufficient in cases of basilar invagination where reduction was easily achieved and there was no significant rotatory component. Discussion with the patient regarding the possibility of extension to the occiput should be made, even if the plan for fusion is to C1. Intraoperative decision making regarding the bone quality, $\mathrm{C} 1$ 

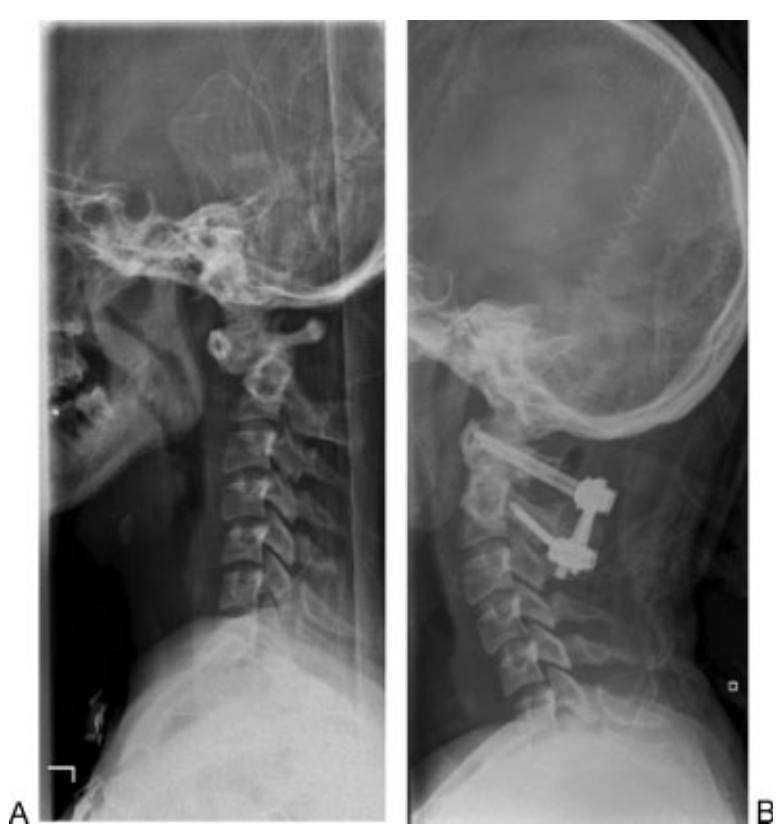

Fig. 10 (A) Preoperative lateral X-ray of cervical spine demonstrating posterior displacement of the dens secondary to C1-C2 instability. (B) Postoperative lateral X-ray of cervical spine demonstrating complete reduction of $\mathrm{C} 1-\mathrm{C} 2$ instability with posterior $\mathrm{C} 1-\mathrm{C} 2$ instrumentation (Harms technique) and fusion.

fixation, ability to achieve adequate reduction and decompression, and preoperative anatomic studies should all be considered when deciding to stop at $\mathrm{C} 1$ versus $\mathrm{C} 0$.

\section{Disclosures}

Dean Chou, Consultant: Globus; Honorarium: DePuy/Synthes, Medtronic

Kris Siemionow, Consultant: Amedica, LifeSpine; Speaker's Bureau: DePuy/Synthes; Globus

Note

This case report is IRB exempt according to the University IRB policy.

Funding

None

\section{References}

1 Abumi K, Takada T, Shono Y, Kaneda K, Fujiya M. Posterior occipitocervical reconstruction using cervical pedicle screws and plate-rod systems. Spine (Phila Pa 1976) 1999;24(14): 1425-1434

2 Goel A, Bhatjiwale M, Desai K. Basilar invagination: a study based on 190 surgically treated patients. J Neurosurg 1998;88(6): 962-968

3 Bhangoo RS, Crockard HA. Transmaxillary anterior decompressions in patients with severe basilar impression. Clin Orthop Relat Res 1999;(359):115-125

4 Botelho RV, Neto EB, Patriota GC, Daniel JW, Dumont PA, Rotta JM. Basilar invagination: craniocervical instability treated with cervical traction and occipitocervical fixation. Case report. J Neurosurg Spine 2007;7(4):444-449

5 Simsek S, Yigitkanli K, Belen D, Bavbek M. Halo traction in basilar invagination: technical case report. Surg Neurol 2006;66(3): 311-314, discussion 314

6 Goel A, Shah A. Reversal of longstanding musculoskeletal changes in basilar invagination after surgical decompression and stabilization. J Neurosurg Spine 2009;10(3):220-227

7 Browd S, Healy LJ, Dobie G, et al. Morphometric and qualitative analysis of congenital occipitocervical instability in children: implications for patients with Down syndrome. J Neurosurg 2006;105 (1, Suppl):50-54

8 Parfenchuck TA, Bertrand SL, Powers MJ, Drvaric DM, Pueschel SM, Roberts JM. Posterior occipitoatlantal hypermobility in Down syndrome: an analysis of 199 patients. J Pediatr Orthop 1994; 14(3):304-308

9 Browd SR, McIntyre JS, Brockmeyer D. Failed age-dependent maturation of the occipital condyle in patients with congenital occipitoatlantal instability and Down syndrome: a preliminary analysis. J Neurosurg Pediatr 2008;2(5):359-364

10 Peng X, Chen L, Wan Y, Zou X. Treatment of primary basilar invagination by cervical traction and posterior instrumented reduction together with occipitocervical fusion. Spine (Phila Pa 1976) 2011;36(19):1528-1531

11 Siemionow K, Neckrysh N. Direct posterior distraction for unreducible cranial settling, surgical technique and review of case series. Presented at: 9th International Meeting on Advanced Spine Techniques (IMAST); July 18-21, 2012; Istanbul, Turkey

12 Hosalkar HS, Gerardi JA, Shaw BA. Combined asymptomatic congenital anterior and posterior deficiency of the atlas. Pediatr Radiol 2001;31(11):810-813

13 Dubousset J. Torticollis in children caused by congenital anomalies of the atlas. J Bone Joint Surg Am 1986;68(2):178-188

14 Wang S, Wang C, Liu Y, Yan M, Zhou H. Anomalous vertebral artery in craniovertebral junction with occipitalization of the atlas. Spine (Phila Pa 1976) 2009;34(26):2838-2842

15 Mummaneni PV, Lu DC, Dhall SS, Mummaneni VP, Chou D. C1 lateral mass fixation: a comparison of constructs. Neurosurgery 2010;66 (3, Suppl)153-160 


\section{Editorial Perspective}

EBSJ editors appreciate the contributions by the case report authors Drs. Siemionow and Chou as well as Dr.Jacob's helpful commentary. These two cases underscore several relevant points:

1. Delay in clinical manifestations: Developmental dysplasias such as in patients with Down syndrome are frequently overlooked and can present late with challenging clinical and social circumstances. Case 1 , with its significant displacement and an os odontoideum, is a not too rare example of a delayed discovery of a considerable craniocervical deformity in a patient with developmental delay.

2. Nomenclature: As Dr. Jacobs correctly points out, there are relatively clearly defined terms that are preferably used for craniocervical deformities-basivertebral invagination, platybasia, and cranial settling, as well as craniocervical assimilation are all distinct entities. Remaining as succinct as possible in our diagnosis semantics is helpful to provide an enhanced foundation for scientific analysis and subsequent discourse.

3. Management: Both the case reports and the commentary underscore the significant implications an extension of a fusion to the occiput can have. In managing patients with developmental delay such as Down syndrome, an additional concern not mentioned in either contribution is that of perioperative care. Patient compliance may be very limited in these cases, and it might be worthwhile to consider the invasiveness of the intended surgery before engaging in such areas as the patient's ability to tolerate intensive care unit care or actively participate in postoperative immobilization protocols. For instance, postoperative immobilization in the mentioned patients may have to follow an "all-or-nothing" principle, in this case no immobilization (since a patient would likely not wear a collar in a predictable fashion) or a halo vest, likely to be applied with more than four pins to minimize risk of pin loosening. Similarly, for any patient with reduced communication abilities, postoperative airway management and specifically clearance of secretions may be a significant challenge.

As always, EBSJ welcomes the comments and viewpoints of its global multidisciplinary readership on the subjects of decision making regarding inclusion or sparing of an extension of craniocervical fusion for upper cervical spine pathology and performing major reconstructive spine surgery in patients with limited communication abilities. 